\title{
Neorickettsia risticii surface-exposed proteins: proteomics identification, recognition by naturally-infected horses, and strain variations
}

\author{
Kathryn E Gibson, Gabrielle Pastenkos, Susanne Moesta and Yasuko Rikihisa*
}

\begin{abstract}
Neorickettsia risticii is the Gram-negative, obligate, and intracellular bacterial pathogen responsible for Potomac horse fever (PHF): an important acute systemic disease of horses. N. risticii surface proteins, critical for immune recognition, have not been thoroughly characterized. In this paper, we identified the 51-kDa antigen (P51) as a major surface-exposed outer membrane protein of older and contemporary strains of $\mathrm{N}$. risticii through mass spectrometry of streptavidin-purified biotinylated surface-labeled proteins. Western blot analysis of sera from naturally-infected horses demonstrated universal and strong recognition of recombinant P51 over other Neorickettsia recombinant proteins. Comparisons of amino acid sequences for predicted secondary structures of P51, as well as Neorickettsia surface proteins 2 (Nsp2) and 3 (Nsp3) among N. risticii strains from horses with PHF during a 26-year period throughout the United States revealed that the majority of variations among strains were concentrated in regions predicted to be external loops of their $\beta$-barrel structures. Large insertions or deletions occurred within a tandem-repeat region in Ssa3. These data demonstrate patterns of geographical association for P51 and temporal associations for Nsp2, Nsp3, and Ssa3, indicating evolutionary trends for these Neorickettsia surface antigen genes. This study showed N. risticii surface protein population dynamics, providing groundwork for designing immunodiagnostic targets for PHF.
\end{abstract}

\section{Introduction}

Discovered in 1984, Neorickettsia (formerly Ehrlichia) risticii is an obligate intracellular bacterium and the causative agent of Potomac horse fever (PHF) [1-3]. The bacterium uses a digenetic trematode to survive and proliferate in its natural lifecycle [4-9]. It is through accidental ingestion of the metacercarial stage of the digenetic trematode within its insect host that the horse becomes infected with N. risticii and develops PHF [6]. PHF is an acute, severe, and potentially fatal disease of horses, normally contracted during the summer months in North America when aquatic insect larvae infested with $N$. risticii-infected digenetic trematodes molt and emerge (hatch) from the water as adults $[6,10]$. Clinical signs range from mild (anorexia, fever, lethargy, and depression) to life-threatening (laminitis, abortion, and diarrhea followed by severe dehydration) $[10,11]$. The administration of tetracyclines at the early

\footnotetext{
* Correspondence: rikihisa.1@osu.edu

Department of Veterinary Biosciences, The Ohio State University College of Veterinary Medicine, 1925 Coffey Rd, Columbus, OH 43210, USA
}

stage of infection is effective, in part by inhibiting bacterial protein synthesis and facilitating lysosome fusion with inclusions containing $N$. risticii [12-15]. Diagnosis of this disease is mainly done by indirect fluorescent-antibody (IFA) test based on N. risticii-infected cells and by nested polymerase chain reaction (PCR) on blood samples [5,16-22]. The only available vaccines are bacterins using the 1984 $N$. risticii type strain, which demonstrate inadequate efficacy $[23,24]$.

It was determined that $N$. risticii has similar genetic, antigenic, and morphologic characteristics to Neorickettsia helminthoeca $[25,26]$, which were the major reasons it, as well as Neorickettsia (formerly Rickettsia, Ehrlichia) sennetsu, was regrouped into the genus Neorickettsia [27]. In addition, the bacterial parasite, known as the Stellantchasmus falcatus (SF) agent, isolated from metacercariae in fish from Japan and Oregon [28-30] belongs to this group. N. risticii also consists of a variety of strains, based on PCR and sequencing of 16S RNA and groEL, Western blot analyses using purified bacteria as antigen, and morphology $[20,22,24,31]$.

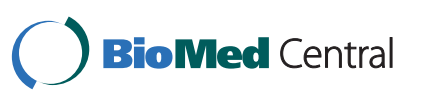

(c) 2011 Gibson et al; licensee BioMed Central Ltd. This is an Open Access article distributed under the terms of the Creative Commons Attribution License (http://creativecommons.org/licenses/by/2.0), which permits unrestricted use, distribution, and reproduction in any medium, provided the original work is properly cited. 
Little is known about $N$. risticii surface-exposed proteins, and this missing information is crucial in the understanding of bacterium-host cell interactions. Antigenic and potential surface proteins ranging between 28 and $110-\mathrm{kDa}$ in mass were previously detected by Western blotting, but these proteins were not identified [32]. Immunoprecipitation of $N$. risticii labeled with $\mathrm{I}^{125}$ and $N$. risticii immune mouse sera revealed potential surface proteins ranging from 25 to $62-\mathrm{kDa}$ in mass, although these proteins were not identified [33]. Antigenic proteins of 70, 55,51 , and 44-kDa masses have been demonstrated utilizing recombinant proteins; again the proteins were not identified [34]. Two highly-immunodominant proteins in two $N$. risticii strains were identified as GroEL and the 51$\mathrm{kDa}$ antigen (P51) [35], but it was not shown whether these proteins were surface exposed. Strain-specific antigen (Ssa) was suggested as a surface immunogenic protein with potential use in vaccine production, although it was not determined to be bacterial surface exposed $[24,36]$.

The identification of Neorickettsia proteins is now achievable with the availability of whole genome sequencing data on both the type strain (Miyayama) of N. sennetsu [37] and the type strain (Illinois) of $N$. risticii [38]. In this paper, we determined 1) major surface proteins by proteomics analysis on $N$. risticii, 2) horse immune recognition of $N$. risticii surface proteins, and 3) strain variations in aligned sequences of these major surface proteins with respect to their predicted secondary structures.

\section{Materials and methods}

\section{Culturing and isolation of $N$. risticii strains}

N. risticii Illinois $^{\mathrm{T}}$ [3] and a Pennsylvania strain (PA-1) [6] were cultured in $\mathrm{P}^{2} 88 \mathrm{D}_{1}$ cells in $75-\mathrm{cm}^{2}$ flasks containing RPMI 1640 (Mediatech, Inc., Herdon, VA, USA) supplemented with $5-10 \%$ fetal bovine serum (FBS) (U.S. Biotechnologies, Inc., Pottstown, PA, USA) and 4-6 mM L-glutamine (Invitrogen, Carlsbad, CA, USA) at $37^{\circ} \mathrm{C}$ under $5 \% \mathrm{CO}_{2}$. N. risticii was isolated from highly-infected $\mathrm{P}_{388 D_{1}}$ cells as previously described for $N$. sennetsu Miyayama $^{\mathrm{T}}[39]$.

\section{Biotinylation and streptavidin-affinity purification of $N$. risticii surface proteins}

Biotinylation of purified $N$. risticii Illinois and PA-1 from twenty-five $75-\mathrm{cm}^{2}$ flasks using EZ Link Sulfo-NHS-SSBiotin (Pierce Biotechnology, Rockford, IL, USA) and subsequent bacterial lysis and collection of solubilized bacterial proteins were performed as previously described [39]. Streptavidin purification of Sulfo-NHS-SS-Biotinylated $N$. risticii proteins was then performed, followed by SDSpolyacrylamide gel electrophoresis (PAGE) and fixation and GelCode blue (Pierce) staining of the gel [39]. Proteins from seven bands from $N$. risticii Illinois and proteins from four bands or band collections from PA-1 were identified by capillary-liquid chromatography-nanospray tandem mass spectrometry (Nano-LC/MS/MS) as previously described [40].

\section{Western blotting using recombinant proteins}

Recombinant P51 (rP51, $57 \mathrm{kDa}$ ), cloned from $N$. risticii Illinois (NRI_0235), and rNsp2 (35 kDa) and rNsp3 (28 $\mathrm{kDa}$ ), cloned from N. sennetsu Miyayama (NSE_0873 and NSE_0875, respectively), were expressed by transformed BL21(DE3) cells using isopropyl- $\beta$-D-thiogalactopyranoside induction and His-tag purified as described previously [30,39]. Recombinant GroEL (55 kDa), derived from N. sennetsu Miyayama (NSE_0642), was acquired from stored aliquots [41]. Fifty $\mu$ g of each recombinant protein were separated by SDS-PAGE, transferred to nitrocellulose membranes, and cut into strips. Western blotting was then performed on these strips using 1:500 dilutions of known positive horse sera samples as determined by IFA [16,21]. The membrane was subsequently incubated with a 1:1000 dilution of horseradish peroxidase-conjugated goat anti-horse (Kirkegaard \& Perry Laboratories, Inc., Gaithersburg, MD, USA) as secondary antibody. Enhanced chemiluminescence (ECL) LumiGLO chemiluminescent reagent (Pierce) and a LAS3000 image documentation system (FUJIFILM Medical Systems USA, Stamford, CT, USA) were used to visualize the protein bands with $300 \mathrm{~s}$ exposure. Bands were aligned using Precision Plus prestained protein standards (Bio-Rad Laboratories, Hercules, CA, USA).

\section{Polymerase chain reaction, sequencing, and sequence alignment}

DNA was purified from buffy coats of PHF-positive horses

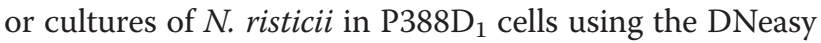
Blood and Tissue Kit (QIAGEN, Valencia, CA, USA), according to manufacturer's instructions. PCR amplification was then performed using either Phusion or Taq DNA polymerase (New England BioLabs, Ipswich, MA, USA) and primers designed for conserved regions through alignment of multiple Neorickettsia spp. and/or N. risticii strains (see Additional file 1). Sequencing was performed by The Ohio State University Plant-Microbe Genomics Facility. Sequences containing whole genes or gene fragments were translated and aligned mainly through the CLUSTAL W (slow/accurate) method in the MegAlign program of DNAStar (DNAStar, Madison, WI, USA); P51 was first aligned by CLUSTAL V (PAM250) method, and Ssa3 was aligned both by CLUSTAL W and manually. External loops were also aligned separately by CLUSTAL W for both P51 and Nsp3. Amino acid (aa) variations in $N$. risticii strains and other Neorickettsia spp. for all proteins were determined in relation to $N$. risticii Illinois. Protein alignments of the same size (including deletions as dashes) were analyzed by PHYLIP (v3.66) to obtain 
bootstrap values for 1000 replicates (using the programs SeqBoot, Protdist, Neighbor, and Consense) and to create dendrograms (using the programs Protdist, Neighbor, and Drawgram) [42]. Protein properties, including antigenicity profiles and $\beta$-sheet predictions were determined using the Protean program (DNAStar). Gene and protein sequence homologies were also demonstrated using Basic Local Alignment Search Tool (BLAST) algorithms, including blastn, protein-protein blastp, and blastp [43,44].

\section{Prediction of secondary structures}

Predictions for Nsp2 and Nsp3 were based on a combination of the programming algorithm in the PREDTMBB web server [45], hydrophobicity and hydrophobic movement profiles [46], and DNAStar MegAlign (DNAStar, Madison, WI, USA) alignment and analyses of all available $N$. risticii strain and Neorickettsia spp. sequences.

\section{GenBank Accession Numbers}

GenBank accession numbers of all sequences determined in this study are shown in Table 1. P51 sequences previously deposited in GenBank used in this study are listed in Table 2. Nsp2 sequences include $N$. risticii Illinois (NRI_0839, YP_003082043) and N. sennetsu Miyayama (YP_746740). Previously-deposited Nsp3 sequences include $N$. risticii Illinois (NRI_0841, YP_003082045) and N. sennetsu Miyayama (YP_506742). Ssa3 sequences include $N$. risticii Illinois (NRI_0872, YP_003082075) and N. sennetsu Miyayama (NSE_0908, YP_506773). The Ssa1 sequence is from N. risticii Illinois (NRI_0870, YP_003082073), and other Ssas are from 25-D (AAC31427) and 90-12 (AAC31428).

\section{Results}

\section{Nano-LC/MS/MS of streptavidin-affinity purified surface} proteins

Given that only the $N$. risticii Illinois genome (NC_013009) has been sequenced [38], these data were used for proteomic analyses. Four $N$. risticii proteins in $N$. risticii Illinois (1984 isolate) and five $N$. risticii proteins (with conserved peptide sequences in relation to $N$. risticii Illinois) in PA-1 (2000 isolate) contained two or more peptide queries identified by Nano-LC/MS/MS (Table 3). Proteins identified for $N$. risticii Illinois were P51, GroEL (NRI_0614), Nsp3, and a conserved hypothetical protein (NRI_0567). The largest protein coverage and the largest number of peptides identified were both from P51. Proteins identified in PA-1 also included P51 and GroEL; the largest number of peptides was from P51. Minor proteins identified in PA-1 strain were DnaK (NRI_0017), ATP synthase F1, alpha subunit (AtpA, NRI_0132), and strain-specific antigen 3 (Ssa3, NRI 0872).
Immune recognition of major surface antigens by PHFpositive horse sera

Bacterial surface-exposed proteins are generally major antigens [47]. Though only Nsp3 was detected on the surface of $N$. risticii Illinois by nano-LC/MS/MS, rNsp2 was included in the Western blotting studies because both Nsp3 and Nsp2 from N. sennetsu Miyayama are significant surface proteins (Figure 1, Table 4) [39]. All 15 PHF-positive samples demonstrated recognition of rP51, with 11 out of 15 sera having strong recognition. N. sennetsu Miyayama GroEL is $98 \%$ identical to $N$. risticii Illinois GroEL, and antisera to rGroEL of $N$. sennetsu cross-reacts with GroEL from multiple species of Rickettsiales, including $N$. risticii [41]. Six out of 15 PHF-positive serum samples demonstrated strong reactivity to rGroEL, with the rest having weak to no reactivity. Nsp2 and Nsp3 from N. sennetsu Miyayama are $83 \%$ and $84 \%$ identical to Nsp2 and Nsp3 from $N$. risticii Illinois, respectively, using protein-protein blastp. Only one serum sample reacted strongly to $\mathrm{rNsp} 2$, with the rest having weak to no reactivity. Three sera reacted strongly to $\mathrm{rNsp} 3$, with the rest having weak to no reactivity. All negative controls did not recognize any of the recombinant proteins.

\section{Sequence variation in P51}

P51 sequences are known to be strain variable $[5,30]$. Since P51 was found to be the major target of horse immune recognition, we examined in which part of the P51 molecule sequence variations occur. N. sennetsu P51 was predicted to have 18 transmembrane $\beta$-barrel proteins with nine external loops [39]. N. sennetsu and the SF agent, which are closely-related to $N$. risticii $[28,30,48]$ were included for comparison. P51 alignments of a total of 52 sequences and sequence fragments from $N$. risticii during a 26-year period throughout the United States revealed high variability within regions corresponding to external loops 2 and 4 (Figure 2). Forty-three P51 sequence fragments (aa 136-176) containing most of external loop 2 (aa 120-176), and 36 P51 sequence fragments (aa 259-286) containing the entire external loop 4 were analyzed using PHYLIP (Figure 3a and 3b). Both loops 2 and 4 created patterns of clustering for sequences from states in the Eastern and Midwestern United States (East/Midwest US) and sequences from Japan, Malaysia, and US states bordering the Pacific Ocean (Pacific coast). The California strain Doc and the Ohio strain 081 did not follow this pattern, both being in East/Midwest US for external loop 2 and in Pacific coast for external loop 4. In external loop 2, $N$. risticii Illinois was only loosely associated with the other East/Midwest US sequences; in external loop 4, N. risticii Illinois tightly clustered with several East/Midwest US sequences. External loop 4 of 081 clustered with the SF agent strains rather than with other $N$. risticii strains. 
Table 1 Sequences amplified for Neorickettsia

\begin{tabular}{|c|c|c|c|c|}
\hline Sample ID ${ }^{a}$ & Location/Year & Fragment size $(b p)^{b}$ & Gene(s) amplified ${ }^{\mathrm{c}}$ & Accession no. \\
\hline \multirow[t]{3}{*}{$\overline{P A-1}$} & Pennsylvania/2000 & 2091 & $n s p 2, n s p 3$ & HQ857586 \\
\hline & & 765 & ssal (p) & HQ857584 \\
\hline & & 1812 & ssa3 & HQ857585 \\
\hline \multirow[t]{3}{*}{ Herodia } & Pennsylvania/1999 & 673 & $p 51(p)$ & HQ857589 \\
\hline & & 2133 & $n s p 2, n s p 3$ & HQ857588 \\
\hline & & 1460 & ssa3 & HQ857587 \\
\hline \multirow[t]{2}{*}{081} & Ohio/1991 & 2420 & $n s p 2, n s p 3$ & HQ857591 \\
\hline & & 717 & ssa3 (p) & HQ857590 \\
\hline \multirow[t]{3}{*}{$\overline{\mathrm{MN}}$} & Minnesota/2002 & 676 & $p 51(p)$ & HQ857594 \\
\hline & & 2156 & nsp2, nsp3 & HQ857593 \\
\hline & & 1029 & $\operatorname{ssa3}(p)$ & HQ857592 \\
\hline \multirow[t]{2}{*}{$\overline{\mathrm{OV}}$} & Kentucky/1993 & 2103 & nsp2, nsp3 & HQ857596 \\
\hline & & 863 & ssa3 & HQ857595 \\
\hline$\overline{\mid A 03-1}$ & lowa/2003 & 1550 & $n s p 2$ (p), nsp3 & HQ875741 \\
\hline \multirow[t]{2}{*}{ IL01-1 } & Illinois/2001 & 623 & nsp2 (p) & HQ875742 \\
\hline & & 489 & nsp3 (p) & HQ875743 \\
\hline IN01-1 & Indiana/2001 & 1879 & $n s p 2(p), n s p 3$ & HQ875744 \\
\hline IN02-1 & Indiana/2002 & 2052 & $n s p 2(p), n s p 3$ & HQ875745 \\
\hline \multirow[t]{2}{*}{ IN02-2 } & Indiana/2002 & 542 & $p 51(p)$ & HQ875747 \\
\hline & & 733 & nsp3 (p) & HQ875746 \\
\hline \multirow[t]{2}{*}{ IN03-1 } & Indiana/2003 & 542 & $p 51(p)$ & HQ906674 \\
\hline & & 2110 & $n s p 2, n s p 3$ & HQ906673 \\
\hline IN03-2 & Indiana/2003 & 1361 & $n s p 2, n s p 3(p)$ & HQ906675 \\
\hline \multirow[t]{5}{*}{ KY03-1 } & Kentucky/2003 & 673 & $p 51(p)$ & HQ906678 \\
\hline & & 594 & p51 (p) & HQ906679 \\
\hline & & 306 & p51 (p) & HQ906680 \\
\hline & & 2095 & $n s p 2, n s p 3$ & HQ906677 \\
\hline & & 1129 & ssa3 (p) & HQ906676 \\
\hline KY03-2 & Kentucky/2003 & 1398 & nsp2, nsp3 (p) & HQ906681 \\
\hline KY03-3 & Kentucky/2003 & 1042 & nsp2 (p), nsp3 (p) & HQ906682 \\
\hline \multirow[t]{3}{*}{$\mathrm{OH} 07-1$} & Ohio/2007 & 259 & $p 51(p)$ & HQ906685 \\
\hline & & 721 & ssal (p) & HQ906683 \\
\hline & & 1739 & ssa3 & HQ906684 \\
\hline $\mathrm{OH} 07-2$ & Ohio/2007 & 259 & $p 51(p)$ & HQ906686 \\
\hline \multirow[t]{2}{*}{$\mathrm{OH} 07-3$} & Ohio/2007 & 1558 & nsp2 (p), nsp3 (p) & HQ906688 \\
\hline & & 995 & ssa3 (p) & HQ906687 \\
\hline \multirow[t]{3}{*}{$\mathrm{OH} 07-4$} & Ohio/2007 & 654 & p51 (p) & HQ906691 \\
\hline & & 1118 & $n s p 2(p), n s p 3(p)$ & HQ906690 \\
\hline & & 1029 & ssa3 (p) & HQ906689 \\
\hline $\mathrm{OH} 10-1$ & Ohio/2010 & 768 & ssa3 (p) & HQ906692 \\
\hline $\mathrm{OH} 10-2$ & Ohio/2010 & 660 & $p 51(p)$ & HQ906693 \\
\hline \multirow[t]{3}{*}{ TN02-1 } & Tennessee/2002 & 676 & $p 51(p)$ & HQ906695 \\
\hline & & 622 & p51 (p) & HQ906696 \\
\hline & & 1893 & $n s p 2$ (p), nsp3 & HQ906694 \\
\hline \multirow[t]{3}{*}{ SF Oregon } & Oregon/2004 & 1171 & nsp2 & HQ906697 \\
\hline & & 842 & nsp3 & HQ906698 \\
\hline & & 370 & ssa3 (p) & HQ906699 \\
\hline
\end{tabular}

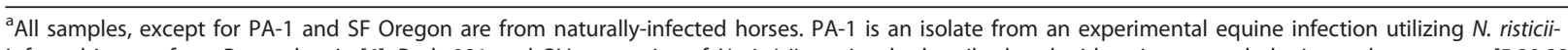
infected insects from Pennsylvania [6]. Both 081 and OV are strains of $N$. risticii previously described and with unique morphologies and sequences [5,20,22]. SF Oregon is a strain of the Stellantchasmus falcatus agent [30].

${ }^{\mathrm{b}}$ The largest fragment size acquired containing the given gene(s) is shown. Multiple fragments may be present for a sample.

${ }^{c} p$, partial sequence for the given gene was obtained. 
Table 2 GenBank P51 sequences used in this study

\begin{tabular}{llll}
\hline Sample ID & $\begin{array}{l}\text { Accession no. } \\
\text { a }\end{array}$ & Sample ID & $\begin{array}{l}\text { Accession } \\
\text { no. }\end{array}$ \\
\hline N. risticii Illinois ${ }^{\top}$ & YP_003081464 & 11908 & AAL79561 \\
PA-1 & AAM18377 & SF Hirose & AAL12490 \\
PA-2 & AAM18376 & SF Oregon & AAR23988 \\
Eclipse & AAC01597 & Dr. Pepper & AAC01596 \\
SqCaddis & AAM18381 & Ms. Annie & AAC01599 \\
SqMouse & AAM18380 & SHSN-1 & AAB95417 \\
S21 & AAG03352 & SHSN-2 & AAB95418 \\
TW2-1 & AAR22503 & SRC & AAB95419 \\
TW2-2 & AAR22504 & SCID/CB17 & AAG09962 \\
25-D & AAB46983 & Snail 2121 & AAF20073 \\
90-12 & AAB46982 & CF1-snail 2121 & AAF20072 \\
CM1-1 & AAR22501 & Shasta-horse & AAF43112 \\
081 & AAG03354 & Caddis-1 & AAF26718 \\
OV & AAG03353 & Caddis-2 & AAF26748 \\
Doc & AAC01595 & Siskiyou horse- & AAF20069 \\
& & 1 & \\
Oregon & AAC01600 & Siskiyou horse- & AAF20070 \\
N. sennetsu & YP_506136 & Siskiyou horse- & AAF20071 \\
Miyayama & & 3 & \\
Kawano & AAR23991 & Juga-1 & AAC01598 \\
Nakazaki & AAR23990 & Stonefly-1 & AAF26749 \\
\hline
\end{tabular}

${ }^{a}$ All sequences listed are P51 sequences that have been previously deposited in GenBank. N. sennetsu Miyayama P51 is NSE_0242.

\section{Sequence variation in Nsp2}

Nsp2 sequences of $N$. risticii, other than the sequence from $N$. risticii Illinois, have not been determined. Nsp2 was predicted to have eight transmembrane $\beta$-barrel domains with four external loops. A total of $20 \mathrm{Nsp} 2$ proteins and protein fragments were aligned. Amino acid variations were determined in relation to $N$. risticii
Illinois. Variations mainly occurred in external loops, with the most variation occurring within external loop 4 (Figure 4a). Full-length Nsp2 (including the signal peptide), with 11 sequences total, as well as the external loop 4 region (aa 244-297) with 19 sequences total were analyzed by PHYLIP (Figure 4b and 4c). For full-length Nsp2 and external loop 4, most $N$. risticii strains obtained after the year 2000 (post-2000 strains, Table 1) were $100 \%$ identical, whereas other strains were more diverse (Figure $4 \mathrm{~b}$ and $4 \mathrm{c}$ ). Nsp2 for both $N$. risticii Illinois and Herodia (which were $100 \%$ identical) were unique to all other $N$. risticii strains. For full-length Nsp2, 081 clustered with SF Oregon, rather than with other N. risticii strains. Additionally, external loop 2 (also demonstrating high variation) showed similar patterns of clustering as seen in full-length Nsp2 and external loop 4; the exceptions were MN, which was $100 \%$ identical to $N$. risticii Illinois and Herodia, and $\mathrm{OH} 07-4$, which had one amino acid difference in comparison to the majority of post-2000 strains in this region (data not shown).

\section{Sequence variation in Nsp3}

Nsp3 sequences of $N$. risticii, except for the sequence from $N$. risticii Illinois have also not been determined. Nsp3 was predicted to have eight transmembrane $\beta$-barrel proteins with four external loops. Alignment of a total of 21 Nsp3 proteins and protein fragments demonstrated the highest variation within predicted external loop 2, yet there was less variation in the $\mathrm{C}$-terminal region comprising external loops 3 and 4 (Figure 5a). Fourteen fulllength Nsp3 sequences (including signal peptides) and 17 external loop 2 regions (aa 102-136) were analyzed by PHLYIP (Figure 5b and 5c). As seen in Nsp2, N. risticii

Table 3 Proteomics-identified proteins for two N.risticii strains

\begin{tabular}{|c|c|c|c|c|c|}
\hline Locus ID & Protein name & Mol Mass (kDa) & $\mathrm{pl}^{\mathrm{a}}$ & $\%$ (query) peptide coverage ${ }^{b}$ & Signal peptide ${ }^{c}$ \\
\hline \multicolumn{6}{|c|}{ N. risticii Illinois ${ }^{\top}$} \\
\hline NRI_0235 & 51-kDa antigen (P51) & 54.9 & 8.44 & $49.2(139)$ & Yes $(20-21)$ \\
\hline NRI_0614 & Heat shock protein 60 (GroEL) & 58.1 & 5.23 & $43.2(36)$ & No \\
\hline NRI_0841 & Neorickettsia surface protein 3 (Nsp3) & 25.7 & 5.96 & $12.0(2)$ & Yes $(24-25)$ \\
\hline NRI_0567 & Conserved hypothetical protein & 50.9 & 4.26 & $9.85(2)$ & No \\
\hline \multicolumn{6}{|l|}{ PA-1 } \\
\hline NRI_0235 & P51 & 54.9 & 8.44 & $34.6(41)$ & Yes $(20-21)$ \\
\hline NRI_0614 & GroEL & 58.1 & 5.23 & $45.6(36)$ & No \\
\hline NRI_0017 & Heat shock protein 70 (DnaK) & 68.4 & 5.18 & $2.20(6)$ & No \\
\hline NRI_0132 & ATP synthase F1, alpha subunit (AtpA) & 55.9 & 5.29 & $2.75(3)$ & No \\
\hline NRI_0872 & Strain-specific surface antigen 3 (Ssa3) & 41.9 & 6.01 & 2.36 or $4.72^{\mathbf{d}}(2)$ & No \\
\hline
\end{tabular}

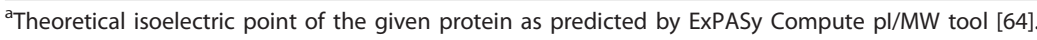

${ }^{b}$ Indicates percentage coverage of proteins by all peptides. Numbers in parentheses are the number of peptide queries for each protein identified in the given band.

'Signal peptide presence as determined by the Center for Biological Sequence Analysis SignalP v.3.0 [65]. Parentheses indicate amino acids between which cleavage is predicted to occur in the given protein.

${ }^{\mathrm{d}}$ The peptide detected twice was within the repeated region of Ssa3, therefore the percentage coverage could be two different percentages. 


\section{PHF sera}

\section{$(k D a) \wedge 23 \star 56 \quad 6189 \wedge^{0} \wedge^{2} \wedge^{3} \wedge^{\star} \wedge^{5}$ rP51}
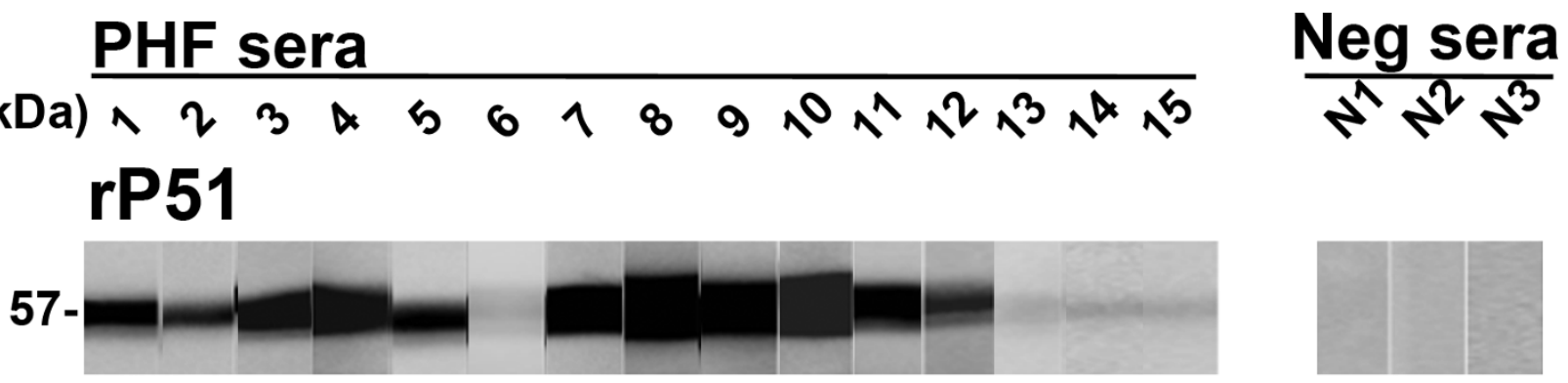

\section{rGroEL}

$55-$

$-$

\section{(1)}

\section{rNsp2}

35-

\section{rNsp3}

\section{8-}

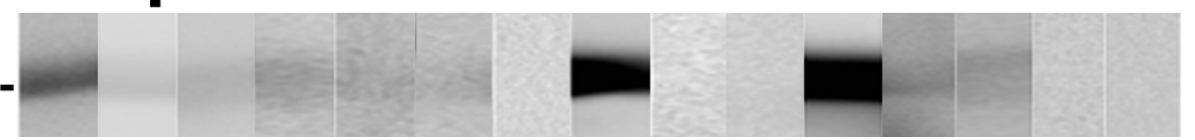

Figure 1 Western blotting against rP51, rGroEL, rNsp2, and rNsp3 using PHF-positive equine sera. Recombinant P51, rGroEL, rNsp2, and rNsp3 were separated by SDS-PAGE and probed with 1:500 dilution of PHF-positive horse sera (PHF sera, 1-15) and negative sera (Neg sera, N1N3). Molecular masses are shown for each recombinant protein. Information regarding the sera samples is given in Table 4.

Illinois had marked differences to other sequences, in particular to most post-2000 strains (Table 1). TN02-1 and IL01-1 had the highest similarity to N. risticii Illinois.

\section{Sequence variation in Ssa3}

Ssa3 sequences of $N$. risticii, other than that of $N$. risticii Illinois have not been ascertained. Ssa3 was included in the analysis, since unknown Ssas were previously reported as major $N$. risticii surface antigens in the 1984 Maryland strain 25-D and the 1990 Maryland strain 9012 [31], and a small amount Ssa3 was detected in both $N$. risticii PA-1 in this study and in $N$. sennetsu Miyayama [39]. There was no signal peptide predicted for Ssa3 [38], and Ssa3 was not predicted to have a $\beta$-barrel structure. It was originally shown that ssas contain a wide variety of mainly small repeats of 10-55 bp in size [31]. Tandem repeats ranging in size from 63-156 bp are present in ssa1, ssa2, and ssa3 of N. risticii Illinois [38]. In particular, the $\mathrm{N}$ terminus of $\mathrm{Ssa} 3$ contains 2.2 copies of a 52 -aa (156 bp) tandem repeat in N. risticii Illinois (aa 53-196) [38]. Thirteen Ssa3 proteins and protein fragments were aligned and compared (Figure 6a). Within this $\mathrm{N}$-terminal repeated region, Neorickettsia spp. consisted of anywhere from zero to four repeated 52-aa peptides arranged in tandem followed by a terminal 40aa peptide similar to the 52 -aa repeats (for $N$. risticii Illinois: $50 \%$ identical, E-value $=6 \times 10^{-8}$, using protein-protein blastp). It appears that the number of 52 -aa repeats increases over time; six post-2000 strains (Table 1) have four repeats. There is further variety in the form of point mutations within the 52 -aa repeats and terminal 40-aa peptide. In addition, the terminal 40 -aa peptide in SF Oregon was truncated by 9 aa (31 aa in length, with the downstream sequence aligning with the other Neorickettsia sequences downstream of their terminal 40-aa peptides). Of note, there are $\beta$-sheets predicted to encompass most of the repeated region (aa 40-67; 76$119 ; 128-167)$ and scattered within the C-terminal region (aa 235-433).

\section{Sequence variation in Ssa1}

Ssa1 sequences of $N$. risticii, other than that of N. risticii Illinois have not been determined. Given the strongest similarities between ssa1 of $N$. risticii Illinois and the unknown ssas from N. risticii strains 25-D (isolated in 1984) and 90-12 (isolated in 1990) [38], two ssa1 fragments 
Table 4 PHF-positive sera from naturally-infected horses and negative sera

\begin{tabular}{|c|c|c|c|c|}
\hline Horse ID ${ }^{a}$ & Clinical signs $^{\mathbf{b}}$ & Location & Year & IFA titer \\
\hline $1(\mathrm{OH} 10-1)$ & A, F, De, Deh, C & Johnstown, $\mathrm{OH}$ & 2010 & $>1: 10,240$ \\
\hline $2(\mathrm{OH} 10-2)$ & A, F, De, C, L, Et, EUTH & Grove City, $\mathrm{OH}$ & 2010 & $>1: 10,240$ \\
\hline 3 & A, F, De, Deh, L, Et, EUTH & Richwood, OH & 2010 & $>1: 10,240$ \\
\hline 4 & $A, D e, F$ & Galloway, OH & 2010 & $>1: 10,240$ \\
\hline 5 & A, De, Deh, F, C, L & Dayton, $\mathrm{OH}$ & 2010 & $>1: 10,240$ \\
\hline 6 & $A, F, C, L, E U T H$ & Loveland, $\mathrm{OH}$ & 2010 & $>1: 10,240$ \\
\hline 7 & U & Indiana & 2010 & $1: 5120$ \\
\hline 8 & A, Di, De, Deh, F, L & Troy, OH & 2008 & 1:1280 \\
\hline 9 & $U$ & Kentucky & 2008 & $1: 1280$ \\
\hline 10 & $U$ & Indiana & 2008 & 1:1280 \\
\hline 11 & A, F, Di, De, Deh & Columbus, $\mathrm{OH}$ & 2008 & 1:1280 \\
\hline 12 & $\mathrm{~A}, \mathrm{~F}, \mathrm{Di}$ & Cattaraugus, NY & 2010 & $1: 640$ \\
\hline 13 & $U$ & Indiana & 2008 & $1: 640$ \\
\hline 14 & $A, F, C$ & Oak Hill, OH & 2008 & $1: 80$ \\
\hline 15 & $A, F$ & Utica, $\mathrm{OH}$ & 2008 & $1: 80$ \\
\hline N1 & $U$ & New Jersey & 2010 & $<1: 20$ \\
\hline N2 & U & Ohio & 2010 & $<1: 20$ \\
\hline N3 & U & New Jersey & 2010 & $<1: 20$ \\
\hline
\end{tabular}

${ }^{\mathrm{a} S e r a} 1$ and 2 are from the same horses as buffy coats $\mathrm{OH} 10-1$ and $\mathrm{OH} 10-2$, respectively, as identified in Table 1.

${ }^{\mathrm{b}} \mathrm{A}$, anorexia; F, fever; De, depression; Deh, dehydration; C, colic; L, laminitis; Et, endotoxemia; EUTH, euthanized; U, Unknown; Di, diarrhea.

were amplified, sequenced, and translated from PA-1 and OH07-1. PA-1 (aa 11-249) and OH07-1 (aa 1-239) Ssa1 fragments were aligned with corresponding regions from N. risticii Illinois Ssa1 (aa 246-469) and the Ssas from 25-D (aa 287-507) and 90-12 (aa 579-817). Ssa1 fragments from PA-1 and OH07-1, which are both post-2000 strains, clustered with the 90-12 Ssa, rather than with the 1980s isolates N. risticii Illinois Ssa1 and 25-D Ssa, suggesting a chronological trend (Figure 6b).

\section{Discussion}

The genes $p 51, n s p 2, n s p 3$, and $s s a 3$ are uniquely evolved in Neorickettsia spp. The gene $p 51$ is a single copy gene and demonstrates only loose associations with other proteins of the family Anaplasmataceae $[37,38]$. The $n s p s$ and ssas are both potential operons, consisting of three genes tandemly arranged [38]. The nsps belong to pfam01617, and similar to Ehrlichia chaffeensis omp-1 ( $p 28)$ genes (also from pfam01617) [49], the proteins

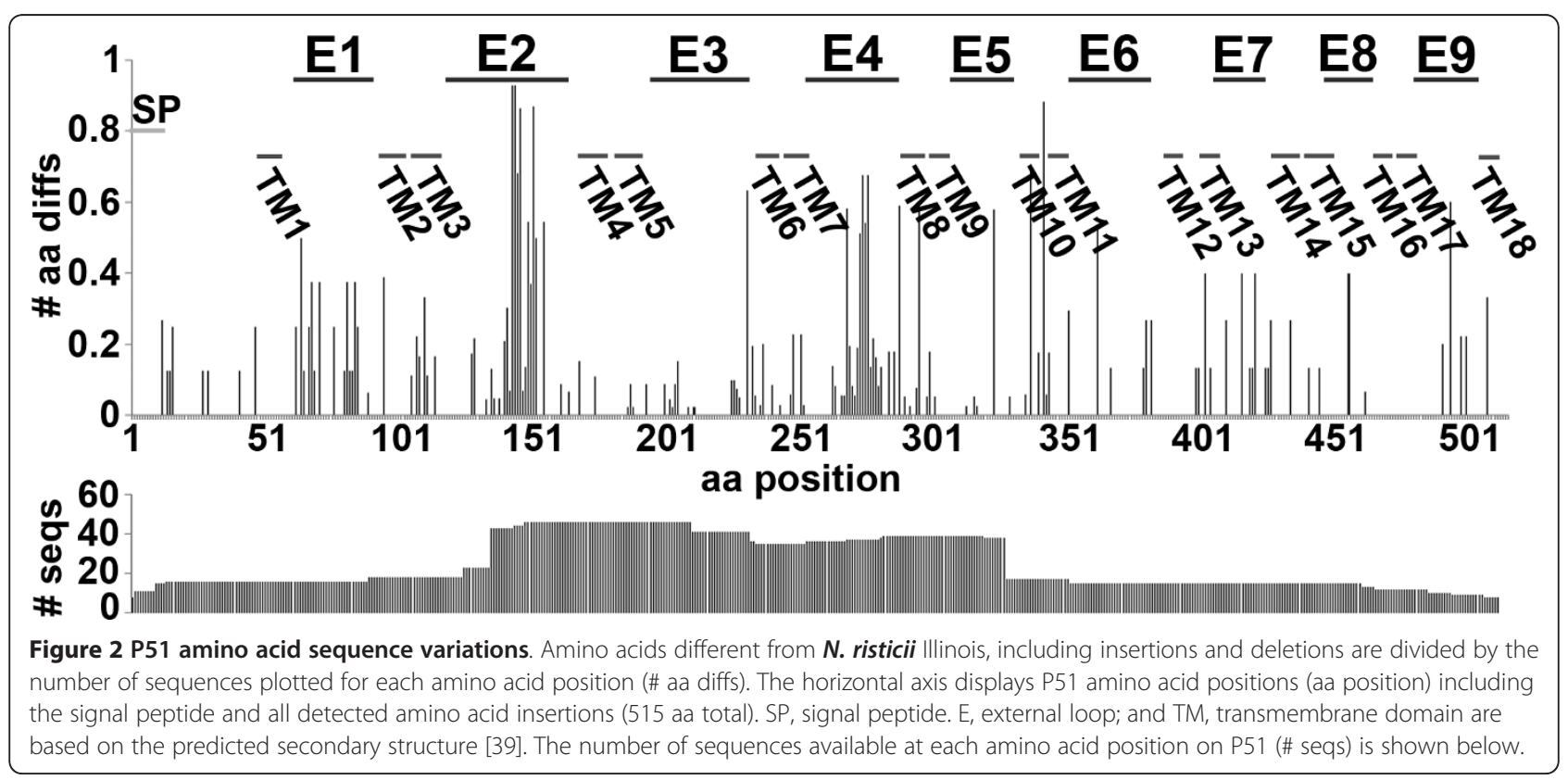




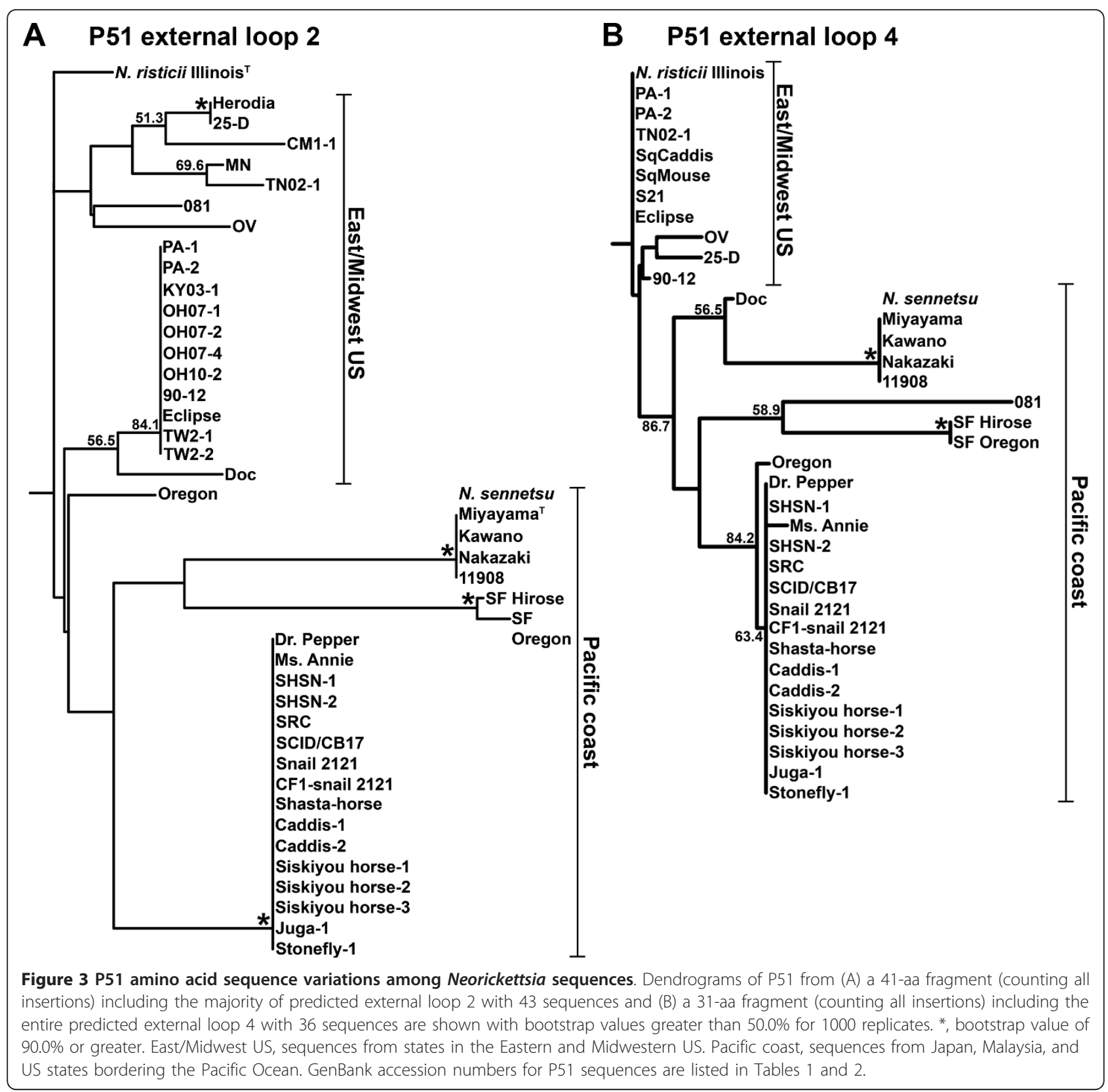

encoded by $n s p 2$ and $n s p 3$ were strain variable. As seen in the ssas, other members of the family Anaplasmataceae have genes encoding proteins containing strain-variable tandem repeats (involving amino acid variation and changes in the numbers of tandem repeats), including Trp120 (formerly gp120), Trp47 (formerly gp47), and VLPT (variable-length PCR target) from E. chaffeensis and Trp140 (formerly gp140), Trp36 (formerly gp36), and gp19 from Ehrlichia canis [50-52]. Of note, the proteins encoded by the ssas are not homologous to any proteins of the family Anaplasmataceae by blastp. Among $p 51$, the nsps, and the ssas, there have been no signs of intragenomic recombination events, which are seen in the Anaplasma p44/msp 2 expression locus [53,54].

Proteomics results performed on two strains of $N$. risticii established that P51 is a dominant surface-expressed protein. The recognition of recombinant P51 by PHF horse sera, even by 1:80 IFA titer sera suggests P51 is expressed and highly recognized within the present day naturallyinfected horses. Despite P51 amino acid sequence variation among $N$. risticii strains, this strong universal recognition by horse immune sera suggests rP51 may serve as a defined serodiagnostic antigen. Furthermore, the study suggests that there are immunodominant conserved 
A

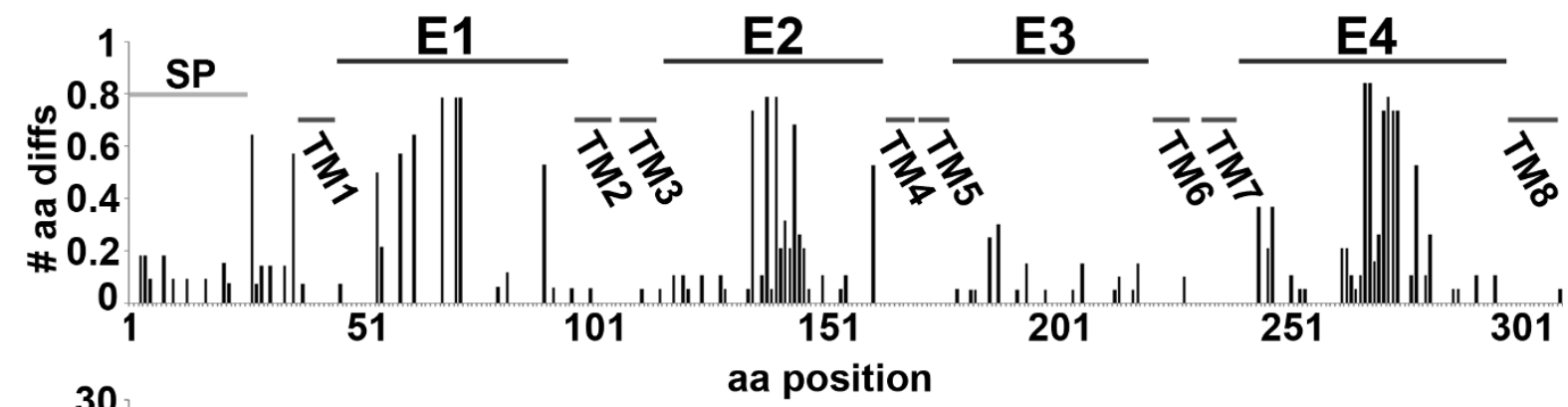

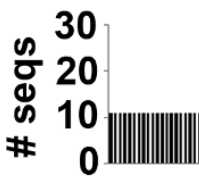

B Nsp2 whole protein

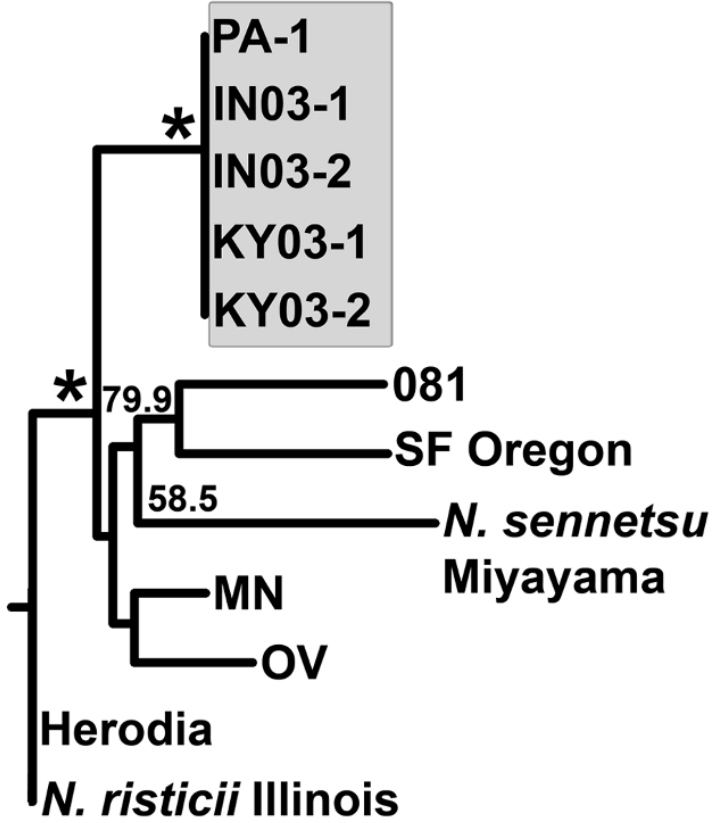

C Nsp2 external loop 4

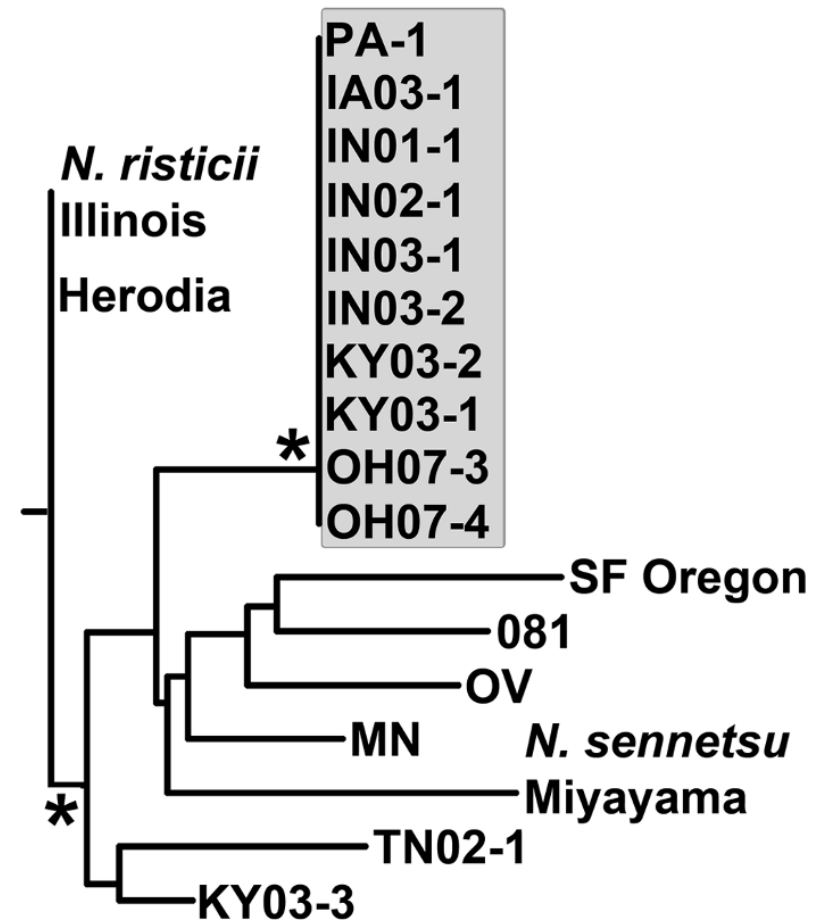

Figure 4 Nsp2 amino acid sequence variations. (A) Amino acids different from $\boldsymbol{N}$. risticii Illinois, including insertions and deletions are divided by the number of sequences plotted for each amino acid position (\# aa diffs). The horizontal axis displays Nsp2 amino acid positions (aa position) including the signal peptide and all detected amino acid insertions (309 aa total). SP, signal peptide. E, external loop; and TM, transmembrane domain are based on the predicted secondary structure. The number of sequences available at each amino acid position on Nsp2 (\# seqs) is shown below. (B) Dendrograms of Nsp2 from the full-length protein, including the signal peptide (12 sequences total) and (C) the predicted external loop 4 (55 aa, including all insertions; 19 sequences total) are shown with bootstrap values greater than 50.0\% for 1000 replicates. *, bootstrap value of $90.0 \%$ or greater. Post-2000 sequences are shown in the shaded area. GenBank accession numbers of new sequences are listed in Table 1.

peptide sequences within P51 which might serve as even more specific PHF diagnostic antigens.

Sequence comparison of these surface-exposed proteins of $N$. risticii strains, with respect to the predicted protein secondary structure, the majority of which are clinical isolates, indicates there are hot spots within the genes with greater strain divergence. These include external loops 2 and 4 in P51, external loop 4 in Nsp2, external loop 2 in Nsp3, and the repeated region of Ssa3. P51 showed strong geographical association; and 


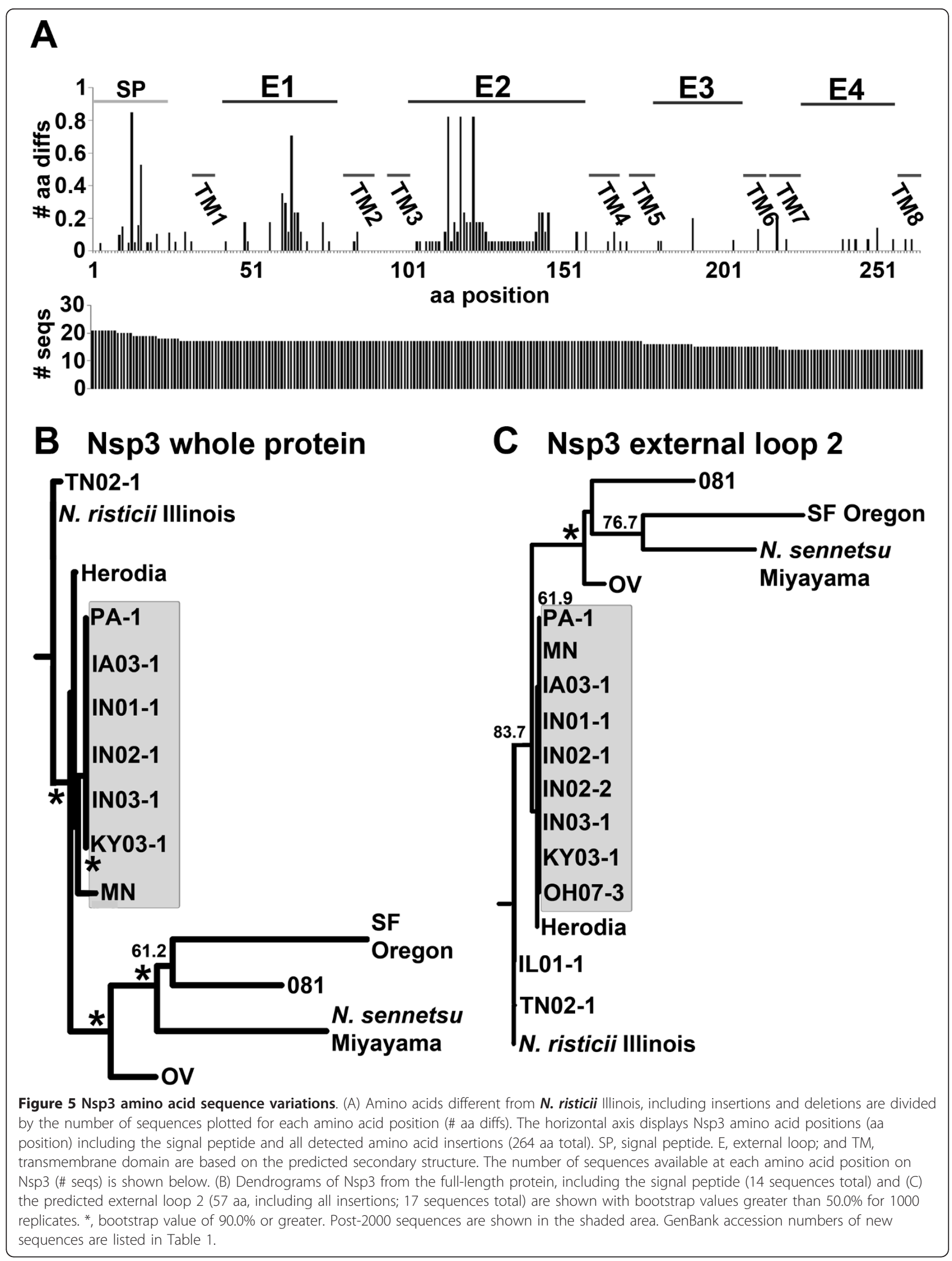




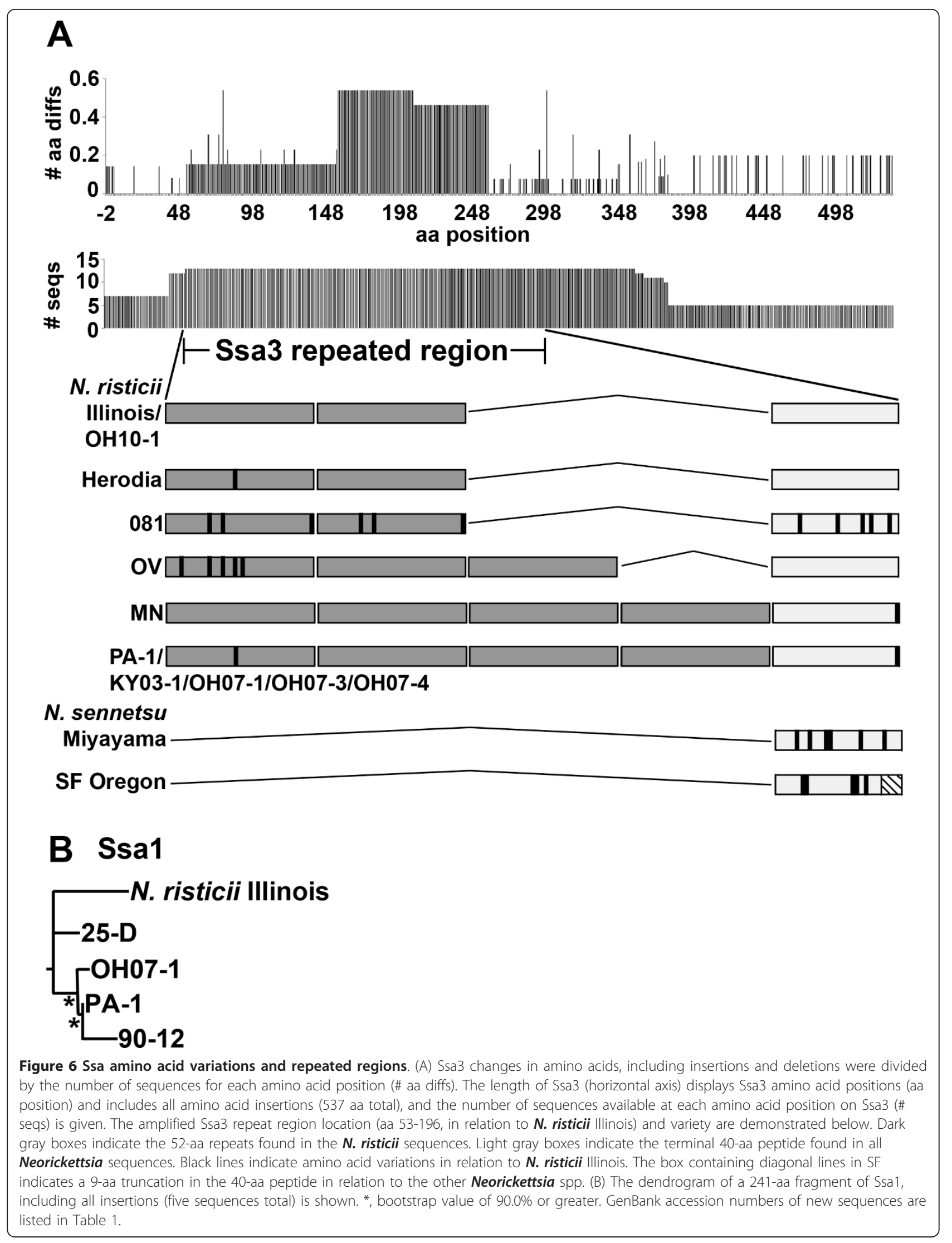


Nsp2, Nsp3, and Ssa3 showed temporal association. Importantly, $N$. risticii Illinois (upon which vaccines for PHF are produced) is distinct from most East/Midwest US strains (P51) and most post-2000 strains (Nsp2, Nsp3, and Ssa3), which may be a contributing factor in PHF vaccine failure $[24,55]$.

There are outlier strains which do not fit the geographical and temporal patterns. These include $081[20,22]$, the Kentucky strain OV [22], and the Kentucky strain Herodia. Unique sequences in other $N$. risticii strains, such as TN02-1 (P51, Nsp2, and Nps3), KY03-3 (Nsp2), IL01-1 (Nsp3), and OH10-1 (Ssa3), suggest that variation contrary to the popular geographical and temporal influences may be more widespread. When additional contemporary sequences and sequences from more varied geographic regions become available, these analyses are expected to improve.

Possible explanations for extensive DNA sequence variation within Neorickettsia include the defective DNA repair systems in both $N$. risticii and $N$. sennetsu $[37,38]$. This would result in higher mutation rates for Neorickettsia [56], which would agree with the temporal changes and the production of outlier strains of $N$. risticii. P51 variation showed substantial geographical association, suggesting these variations were selected under local environmental pressures. It is possible that geographical association of $N$. risticii sequence variation is due to $N$. risticii strains being selected within essential reservoir trematode populations. In addition, diverse $N$. risticii strains may have emerged due to selective pressures inflicted on the infected trematodes and/or on the trematodes' hosts [4-9,57-59]. Humoral immunity would thus not play any direct role in creating genetic diversity within $N$. risticii populations. Since Neorickettsia spp. are known ( $N$. risticii and $N$. helminthoeca) and suspected to be vertically transmitted within their trematode hosts $[8,13,60]$, mammalian infection is not expected to be required for maintaining Neorickettsia in the natural environment.

Regardless the cause, this genetic variation would result in increased $N$. risticii survival as a species. $N$. risticii surface protein genetic diversity revealed in the present study will help in understanding variations in PHF virulence and clinical signs. It may also be possible to use this new molecular knowledge for vaccine development. It would, however necessitate taking into account that the pathogen is an obligate intracellular pathogen, indicating that not only humoral immune responses, but also cell-mediated immunity would play an active role in preventing bacterial infection [61-63].

Genes encoding the two original Ssas, called P85 (90-12) and P50 (25-D) are most related to ssa 1 from $N$. risticii Illinois $[24,31,38,55]$, but they also show similarities to $s s a 2$ and the non-coding region between ssa 1 and ssa 2 using blastn. Although both are Maryland isolates, the 25-D strain was isolated six years earlier than the 90-12 strain [31], suggesting both temporal variation and the potential development of chimeras of multiple Ssas and non-coding regions in P50, P85, and post-2000 Ssa1 (due to the similarities of PA-1 and OH07-1 Ssa1 fragments to P85). It is possible that the high variability of Ssa1 may have prevented PA-1 Ssa1 from being identified by proteomics. However, there is the obvious lack of large numbers of peptides identified by proteomics for Ssas in N. risticii Illinois using the isogenic Illinois strain sequence data and in N. sennetsu using Miyayama isogenic strain data [39]. It is likely that Ssas are not a dominant surface protein in mammalian cells.

In conclusion, our data demonstrate the variety present within major surface proteins of $N$. risticii, and they suggest conservation among geographical regions and time periods. In addition, P51 is implicated as the major surface antigen of $N$. risticii. These data will be valuable in developing better diagnostic methods and may help in the development of more efficacious vaccines.

\section{Additional material}

Additional file 1: Supplemental Table 1. Primers utilized for PCR amplification. Word document demonstrating primers utilized for PCR amplification of $p 51, n s p 2, n s p 3$, ssa1, and ssa3.

\section{Acknowledgements}

We would like to thank the members of the Mass Spectrometry and Proteomics Facility, including Dr Kari Green-Church for their expertise and assistance. We would like to thank Dr Mingqun Lin for his technical advice and assistance and Dr Koshiro Miura for his assistance in training GP. This work was funded by grant R01Al047885 from the National Institutes of Health. KEG was partially supported by T32 RR0070703, and GP and SM were funded by T35 RR021310 from the National Institutes of Health.

\section{Authors' contributions}

KEG drafted the manuscript, designed primers, performed PCR and overall sequence analyses, and created secondary structures and dendrograms. GP designed primers, performed PCR, and performed preliminary sequence analyses. SM performed all SDS-PAGE and Western blotting experiments and gathered clinical data. YR edited the manuscript and supervised all research. All authors read and approved the final manuscript.

\section{Competing interests}

The authors declare that they have no competing interests.

Received: 11 March 2011 Accepted: 2 June 2011 Published: 2 June 2011

\section{References}

1. Rikihisa Y, Perry B: Causative agent of Potomac horse fever. Vet Rec 1984, 115:554-555

2. Rikihisa $Y$, Perry $B$, Cordes D: Rickettsial link with acute equine diarrhoea. Vet Rec 1984, 115:390

3. Holland CJ, Ristic M, Cole Al, Johnson P, Baker G, Goetz T: Isolation, experimental transmission, and characterization of causative agent of Potomac horse fever. Science 1985, 227:522-524.

4. Barlough JE, Reubel GH, Madigan JE, Vredevoe LK, Miller PE, Rikihisa Y. Detection of Ehrlichia risticii the agent of Potomac horse fever in 
freshwater stream snails (Pleuroceridae Juga spp.) from northern California. Appl Environ Microbiol 1998, 64:2888-2893.

5. Kanter M, Mott J, Ohashi N, Fried B, Reed S, Lin YC, Rikihisa Y: Analysis of $16 \mathrm{~S}$ rRNA and 51-kilodalton antigen gene and transmission in mice of Ehrlichia risticii in virgulate trematodes from Elimia livescens snails in Ohio. J Clin Microbiol 2000, 38:3349-3358.

6. Mott J, Muramatsu Y, Seaton E, Martin C, Reed S, Rikihisa Y: Molecular analysis of Neorickettsia risticii in adult aquatic insects in Pennsylvania, in horses infected by ingestion of insects, and isolated in cell culture. J Clin Microbiol 2002, 40:690-693.

7. Chae JS, Pusterla N, Johnson E, Derock E, Lawler SP, Madigan JE: Infection of aquatic insects with trematode metacercariae carrying Ehrlichia risticii, the cause of Potomac horse fever. J Med Entomol 2000, 37:619-625.

8. Gibson KE, Rikihisa Y, Zhang C, Martin C: Neorickettsia risticii is vertically transmitted in the trematode Acanthatrium oregonense and horizontally transmitted to bats. Environ Microbiol 2005, 7:203-212.

9. Gibson KE, Rikihisa Y: Molecular link of different stages of the trematode host of Neorickettsia risticii to Acanthatrium oregonense. Environ Microbiol 2008, 10:2064-2073.

10. Knowles RC, Anderson C, Shipley W, Whitlock R, Perry B, Davidson J: Acute Equine Diarrhea Syndrome (AEDS): A Preliminary Report. In Proceedings of the 29th annual convention of the American Association of Equine Practitioners. Edited by: Milne FJ. Las Vegas, Nevada: American Association of Equine Practitioners; 1984:353-357.

11. Long MT, Goetz TE, Kakoma I, Whiteley HE, Lock TE, Holland CJ, Foreman $\mathrm{JH}$, Baker GJ: Evaluation of fetal infection and abortion in pregnant ponies experimentally infected with Ehrlichia risticii. Am J Vet Res 1995, 56:1307-1316.

12. Rikihisa Y, Jiang BM: In vitro susceptibilities of Ehrlichia risticii to eight antibiotics. Antimicrob Agents Chemother 1988, 32:986-991.

13. Rikihisa Y, Dumler JS, Dasch GA: Neorickettsia. In The Proteobacteria, Part C, Bergey's Manual of Systematic Bacteriology. Volume 2. 2 edition. Edited by: Garrity GM, Brenner DJ, Krieg NR, Staley JT. New York, NY Springer; 2005:132-137.

14. Rikihisa Y: Rickettsial Diseases. In Equine Internal Medicine.. 2 edition. Edited by: Reed SM, Bayly WM, Sellon DC. Philadelphia, PA: W. B. Saunders; 2004:96-109.

15. Wells MY, Rikihisa Y: Lack of lysosomal fusion with phagosomes containing Ehrlichia risticii in $\mathrm{P}_{388} \mathrm{D}_{1}$ cells: abrogation of inhibition with oxytetracycline. Infect Immun 1988, 56:3209-3215.

16. Mott J, Rikihisa Y, Zhang Y, Reed SM, Yu CY: Comparison of PCR and culture to the indirect fluorescent-antibody test for diagnosis of Potomac horse fever. J Clin Microbiol 1997, 35:2215-2219.

17. Ristic M, Holland CJ, Dawson JE, Sessions J, Palmer J: Diagnosis of equine monocytic ehrlichiosis (Potomac horse fever) by indirect immunofluorescence. J Am Vet Med Assoc 1986, 189:39-46.

18. Rikihisa Y, Reed SM, Sams RA, Gordon JC, Pretzman Cl: Serosurvey of horses with evidence of equine monocytic ehrlichiosis. J Am Vet Med Assoc 1990, 197:1327-1332.

19. Rikihisa Y: The tribe Ehrlichieae and ehrlichial diseases. Clin Microbiol Rev 1991, 4:286-308.

20. Chaichanasiriwithaya W, Rikihisa Y, Yamamoto S, Reed S, Crawford TB, Perryman LE, Palmer GH: Antigenic, morphologic, and molecular characterization of new Ehrlichia risticii isolates. J Clin Microbiol 1994, 32:3026-3033.

21. Pretzman Cl, Rikihisa Y, Ralph D, Gordon JC, Bech-Nielsen S: Enzyme-linked immunosorbent assay for Potomac horse fever disease. J Clin Microbiol 1987, 25:31-36.

22. Wen B, Rikihisa Y, Fuerst PA, Chaichanasiriwithaya W: Diversity of 16S rRNA genes of new Ehrlichia strains isolated from horses with clinical signs of Potomac horse fever. Int J Syst Bacteriol 1995, 45:315-318.

23. Palmer JE: Prevention of Potomac horse fever. Cornell Vet 1989, 79:201-205.

24. Dutta SK, Vemulapalli R, Biswas B: Association of deficiency in antibody response to vaccine and heterogeneity of Ehrlichia risticii strains with Potomac horse fever vaccine failure in horses. J Clin Microbiol 1998, 36:506-512.

25. Rikihisa Y, Stills H, Zimmerman G: Isolation and continuous culture of Neorickettsia helminthoeca in a macrophage cell line. J Clin Microbiol 1991, 29:1928-1933.
26. Pretzman C, Ralph D, Stothard DR, Fuerst PA, Rikihisa Y: $16 \mathrm{~S}$ rRNA gene sequence of Neorickettsia helminthoeca and its phylogenetic alignment with members of the genus Ehrlichia. Int I Syst Bacteriol 1995, 45:207-211.

27. Dumler JS, Barbet AF, Bekker CP, Dasch GA, Palmer GH, Ray SC, Rikihisa Y, Rurangirwa FR: Reorganization of genera in the families Rickettsiaceae and Anaplasmataceae in the order Rickettsiales: unification of some species of Ehrlichia with Anaplasma, Cowdria with Ehrlichia and Ehrlichia with Neorickettsia, descriptions of six new species combinations and designation of Ehrlichia equi and 'HGE agent' as subjective synonyms of Ehrlichia phagocytophila. Int I Syst Evol Microbiol 2001, 51:2145-2165.

28. Fukuda T, Yamamoto S: Neorickettsia-like organism isolated from metacercaria of a fluke, Stellantchasmus falcatus. Jpn J Med Sci Biol 1981, 34:103-107.

29. Wen B, Rikihisa Y, Yamamoto S, Kawabata N, Fuerst PA: Characterization of the SF agent, an Ehrlichia sp. isolated from the fluke Stellantchasmus falcatus, by $16 \mathrm{~S}$ rRNA base sequence, serological, and morphological analyses. Int J Syst Bacteriol 1996, 46:149-154.

30. Rikihisa Y, Zhang C, Kanter M, Cheng Z, Ohashi N, Fukuda T: Analysis of p51, groESL, and the major antigen P51 in various species of Neorickettsia, an obligatory intracellular bacterium that infects trematodes and mammals. J Clin Microbiol 2004, 42:3823-3826.

31. Biswas B, Vemulapalli R, Dutta SK: Molecular basis for antigenic variation of a protective strain-specific antigen of Ehrlichia risticii. Infect Immun 1998, 66:3682-3688.

32. Dutta SK, Mattingly BL, Shankarappa B: Antibody response to Ehrlichia risticii and antibody reactivity to the component antigens in horses with induced Potomac horse fever. Infect Immun 1989, 57:2959-2962.

33. Kaylor PS, Crawford TB, McElwain TF, Palmer GH: Passive transfer of antibody to Ehrlichia risticii protects mice from ehrlichiosis. Infect Immun 1991, 59:2058-2062.

34. Dutta SK, Shankarappa B, Mattingly-Napier BL: Molecular cloning and analysis of recombinant major antigens of Ehrlichia risticii. Infect Immun 1991, 59:1162-1169.

35. Vemulapalli R, Biswas B, Dutta SK: Cloning and molecular analysis of genes encoding two immunodominant antigens of Ehrlichia risticii. Microb Pathog 1998, 24:361-372.

36. Vemulapalli R, Biswas B, Dutta SK: Studies with recombinant proteins of Ehrlichia risticii: identification of strain-specific antigen as a protective antigen. Vet Parasitol 1998, 76:189-202.

37. Hotopp JC, Lin M, Madupu R, Crabtree J, Angiuoli SV, Eisen J, Seshadri R, Ren Q, Wu M, Utterback TR, Smith S, Lewis M, Khouri H, Zhang C, Niu H, Lin Q, Ohashi N, Zhi N, Nelson W, Brinkac LM, Dodson RJ, Rosovitz MJ, Sundaram J, Daugherty SC, Davidsen T, Durkin AS, Gwinn M, Haft DH, Selengut JD, Sullivan SA, et al: Comparative genomics of emerging human ehrlichiosis agents. PLOS Genet 2006, 2:e21.

38. Lin M, Zhang C, Gibson K, Rikihisa Y: Analysis of complete genome sequence of Neorickettsia risticii: causative agent of Potomac horse fever. Nucleic Acids Res 2009, 37:6076-6091.

39. Gibson K, Kumagai Y, Rikihisa Y: Proteomic analysis of Neorickettsia sennetsu surface-exposed proteins and porin activity of the major surface protein P51. J Bacteriol 2010, 192:5898-5905.

40. Ge Y, Rikihisa Y: Surface-exposed proteins of Ehrlichia chaffeensis. Infect Immun 2007, 75:3833-3841.

41. Zhang Y, Ohashi N, Lee EH, Tamura A, Rikihisa Y: Ehrlichia sennetsu groE operon and antigenic properties of the GroEL homolog. FEMS Immunol Med Microbiol 1997, 18:39-46.

42. Felsenstein J: PHYLIP - Phylogeny Inference Package (Version 3.2). Cladistics 1989, 5:164-166.

43. Zhang Z, Schwartz S, Wagner L, Miller W: A greedy algorithm for aligning DNA sequences. J Comput Biol 2000, 7:203-214.

44. Altschul SF, Madden TL, Schaffer AA, Zhang J, Zhang Z, Miller W, Lipman DJ: Gapped BLAST and PSI-BLAST: a new generation of protein database search programs. Nucleic Acids Res 1997, 25:3389-3402.

45. Bagos PG, Liakopoulos TD, Spyropoulos IC, Hamodrakas SJ: PRED-TMBB: a web server for predicting the topology of beta-barrel outer membrane proteins. Nucleic Acids Res 2004, 32:W400-404.

46. Jeanteur $\mathrm{D}$, Lakey JH, Pattus F: The bacterial porin superfamily: sequence alignment and structure prediction. Mol Microbiol 1991, 5:2153-2164.

47. Brogden KA: Virulence mechanisms of bacterial pathogens. 4 edition. Washington, D.C.: ASM Press; 2007. 
48. Rikihisa Y: Cross-reacting antigens between Neorickettsia helminthoeca and Ehrlichia species, shown by immunofluorescence and Western immunoblotting. J Clin Microbiol 1991, 29:2024-2029.

49. Miura K, Rikihisa Y: Virulence potential of Ehrlichia chaffeensis strains of distinct genome sequences. Infect Immun 2007, 75:3604-3613.

50. Sumner JW, Childs JE, Paddock CD: Molecular cloning and characterization of the Ehrlichia chaffeensis variable-length PCR target: an antigen-expressing gene that exhibits interstrain variation. J Clin Microbiol 1999, 37:1447-1453.

51. Zhang X, Luo T, Keysary A, Baneth G, Miyashiro S, Strenger C, Waner T, McBride JW: Genetic and antigenic diversities of major immunoreactive proteins in globally distributed Ehrlichia canis strains. Clin Vaccine Immunol 2008, 15:1080-1088.

52. Doyle CK, Cardenas AM, Aguiar DM, Labruna MB, Ndip LM, Yu XJ, McBride JW: Molecular characterization of $E$. canis gp36 and $E$. chaffeensis gp47 tandem repeats among isolates from different geographic locations. Ann N Y Acad Sci 2005, 1063:433-435.

53. Lin $\mathrm{Q}$, Rikihisa $Y$, Ohashi N, Zhi N: Mechanisms of variable $p 44$ expression by Anaplasma phagocytophilum. Infect Immun 2003, 71:5650-5661.

54. Barbet AF, Meeus PF, Belanger M, Bowie MV, Yi J, Lundgren AM, Alleman AR, Wong SJ, Chu FK, Munderloh UG, Jauron SD: Expression of multiple outer membrane protein sequence variants from a single genomic locus of Anaplasma phagocytophilum. Infect Immun 2003, 71:1706-1718.

55. Vemulapalli R, Biswas B, Dutta SK: Pathogenic, immunologic, and molecular differences between two Ehrlichia risticii strains. J Clin Microbiol 1995, 33:2987-2993.

56. LeClerc JE, Li B, Payne WL, Cebula TA: High mutation frequencies among Escherichia coli and Salmonella pathogens. Science 1996, 274:1208-1211.

57. Pusterla N, Johnson EM, Chae JS, Madigan JE: Digenetic trematodes, Acanthatrium sp. and Lecithodendrium sp., as vectors of Neorickettsia risticii, the agent of Potomac horse fever. J Helminthol 2003, 77:335-339.

58. Park BK, Kim MJ, Kim EH, Kim MS, Na DG, Chae JS: Identification of trematode cercariae carrying Neorickettsia risticii in freshwater stream snails. Ann N Y Acad Sci 2003, 990:239-247.

59. Pusterla N, Madigan JE, Chae JS, DeRock E, Johnson E, Pusterla JB: Helminthic transmission and isolation of Ehrlichia risticii, the causative agent of Potomac horse fever, by using trematode stages from freshwater stream snails. J Clin Microbiol 2000, 38:1293-1297.

60. Nyberg PA, Knapp SE, Millemann RE: "Salmon poisoning" disease. IV. Transmission of the disease to dogs by Nanophyetus salmincola eggs. J Parasitol 1967, 53:694-699.

61. Park J, Rikihisa Y: L-arginine-dependent killing of intracellular Ehrlichia risticii by macrophages treated with gamma interferon. Infect Immun 1992, 60:3504-3508.

62. Park J, Rikihisa Y: Inhibition of Ehrlichia risticii infection in murine peritoneal macrophages by gamma interferon, a calcium ionophore, and concanavalin A. Infect Immun 1991, 59:3418-3423.

63. Rikihisa $Y$ : Protection against murine potomac horse fever by an inactivated Ehrlichia risticii vaccine. Vet Microbiol 1991, 27:339-350.

64. Gasteiger E, Hoogland C, Gattiker A, Duvaud S, Wilkins MR, Appel RD, Bairoch A: Protein identification and analysis tools on the ExPASy server. In The proteomics protocols handbook. Edited by: Walker JM. Totowa, N.J: Humana Press; 2005:571-607.

65. Bendtsen JD, Nielsen H, von Heijne G, Brunak S: Improved prediction of signal peptides: SignalP 3.0. J Mol Biol 2004, 340:783-795.

doi:10.1186/1297-9716-42-71

Cite this article as: Gibson et al:: Neorickettsia risticii surface-exposed proteins: proteomics identification, recognition by naturally-infected horses, and strain variations. Veterinary Research 2011 42:71.

\section{Submit your next manuscript to BioMed Central and take full advantage of:}

- Convenient online submission

- Thorough peer review

- No space constraints or color figure charges

- Immediate publication on acceptance

- Inclusion in PubMed, CAS, Scopus and Google Scholar

- Research which is freely available for redistribution

Submit your manuscript at www.biomedcentral.com/submit
Biomed Central 